\title{
Relações entre a literatura infantil angolana, de José Eduardo Agualusa, e o cinema italiano, de Federico Fellini.
}

\author{
Regina Chamlian ${ }^{1}$
}

RESUMO: Este trabalho tem por finalidade apontar relações intertextuais existentes entre "O País dos Contrários", um dos dez contos que integram Estranhões e Bizarrocos e outros seres sem exemplo, livro para crianças publicado no ano 2000, do autor angolano José Eduardo Agualusa, e "A tentação do Dr. Antonio", filme do cineasta italiano Federico Fellini, um dos quatro episódios do longa-metragem Bocaccio 70, produzido por Carlo Ponti em 1962, e que, por sua vez, se relaciona com Decameron, de Giovanni Bocaccio, obra literária do século XIV.

ABSTRACT: This work aims to point out some intertextual relations between "O País dos Contrários", one of the ten short-stories that integrates Estranhões e Bizarrocos e outros seres sem exemplo, a book for children published in 2000, by the Angolan author José Eduardo Agualusa, and "A tentação do Dr. Antônio", a film by Federico Fellini, one of the four episodes of Bocaccio 70, a feature film produced by Carlo Ponti in 1962 and related to Giovanni Bocaccio's Decameron, a literary masterpiece of the 14th century.

PALAVRAS-CHAVE: Intertextualidade, literatura, cinema, amor, alteridade.

KEYWORDS: Intertextuality, literature, cinema, love, otherness.

Estranhões e Bizarrocos [estórias para adormecer anjos], livro do angolano José Eduardo Agualusa, é uma antologia de contos endereçados às crianças. São dez narrativas contemporâneas, construídas através de prosa bem cuidada, rica em trocadilhos, brincadeiras formais, jogos de palavras e jogos intertextuais de tom

1 Mestranda em Estudos Comparados de Literaturas de Língua Portuguesa. Universidade de São Paulo (USP). Bolsista CAPES. Pesquisa: Análise comparativa entre as obras Berenice detetive, de João Carlos Marinho, e Jaime Bunda, agente secreto, de Pepetela. 
bem-humorado e caráter fantástico, cujos personagens parecem sempre se engajar numa busca existencial não-conformista e emancipatória.

Tais narrativas são: Estranhões \& Bizarrocos e outros seres sem exemplo; Sábios como camelos; A menina de peluche; O peixinho que descobriu o mar; O primeiro pirilampo do mundo; O país dos contrários; O caçador de borboletas; O pai que se tornou mãe; O sonhador e A menina que queria ser maçã.

Dentre os dez títulos acima, escolhi, para analisar um pouco mais detidamente, O País dos Contrários.

\section{O País dos Contrários}

Neste conto, o gato Felini se apaixona perdidamente por uma vaca, e passa a viver faminto e magro pelos telhados, sofrendo de amor. Todos riem dele, sua mãe, seus colegas, e Graciosa, a vaca, não lhe dá a menor atenção. A mãe de Felini diz que vacas gostam de bois. Ele começa a pastar e cresce até atingir o tamanho de um boi. Mas a vaca se apavora quando vê aquele gato-boi, e foge. Os demais também o olham com horror. Felini, então, decide ir viver em outro país e, depois de muito viajar, chega ao País dos Contrários. Lá, um elefante é tão pequeno quanto uma formiga. O gato Felini lhe conta que saiu de seu país porque ali era visto como se fosse um monstro. O elefante tranqüiliza-o porque, no País dos Contrários, todos os gatos são como ele. E tudo parece ir muito bem para o gato Felini, até que ele se apaixona outra vez. Agora, por uma vaca tão pequena que nem lhe alcança os calcanhares.

Dentre as várias abordagens possíveis para a leitura de O País

dos Contrários, interessou-me particularmente aquela suscitada a partir do nome da personagem principal: Felini. Tal nome poderia ser encarado apenas como dupla referência brincalhona: à palavra 'gato', que é um felino; e ao grande cineasta italiano do século 20, Federico Fellini. 
Também poderia ser entendido como homenagem mais ampla de Agualusa à poética felliniana, de imagens fantásticas e surreais, livre imaginação e fantasia, com a qual o seu trabalho, a julgar por Estranhões e Bizarrocos, mantém alguns vínculos.

Seria necessário, então, para ventilar essas questões, inventariar a obra cinematográfica de Fellini para ver qual relação, além das mencionadas no parágrafo acima, poderia ela ter com "O País dos Contrários”.

Essa busca levou-me a "A tentação do Dr. Antonio", médiametragem de Fellini que integra o filme em episódios Boccaccio'70, clássico do cinema italiano lançado em 1962.

\section{A tentação do Dr. Antonio}

“A tentação do Dr. Antonio” é narrado pelo próprio Eros, um anjinho provocante e brincalhão.

E Eros nos conta que tem uma pessoa que anda lhe dando muito trabalho. Trata-se de Antonio Mazzuollo, um católico ultra-moralista que faz parte de uma comissão de censura do Ministério dos Espetáculos e costuma importunar os casais que namoram dentro dos carros, nos arredores de Roma: ele joga holofote na cara deles, faz discursos inflamados contra a "pouca vergonha", chama a polícia... Eros não sabe o que fazer com ele.

Até que, certo dia, um gigantesco outdoor é colocado bem em frente ao apartamento do Dr. Antonio.

Nesse cartaz, a atriz e modelo sueca Anita Ekberg, em pose sensual e provocante, com um vestido generosamente decotado, oferece um copo de leite.

Antonio Mazzuolo, indignado, vai a todos os lugares (prefeituras, igreja...), sobe e desce escadarias (em cenas "kafkianas") e faz inúmeras gestões até conseguir que cubram o outdoor.

Mas, chove a cobertura se desfaz, e, de seu apartamento, ao olhar o retrato do cartaz, ele vê a Anita Ekberg fazendo-lhe caretas e pondo 
chifrinhos na testa com a mão. Antonio, então, pega um guarda-chuva e sai. Ao aproximar-se do cartaz vê o copo de leite - enorme - no chão. O copo é do tamanho dele.

E onde está Anita? Ela saiu do quadro.

Ela é gigantesca, tem o tamanho que vemos no outdoor.

Os dois conversam, ela acaba colocando o pequeno Antônio entre os seios, e nessa cena acabamos percebendo que na verdade Antonio está obcecado, apaixonado por ela. Anita, em certo momento, fica do tamanho dele, mas ele é um chato e ela volta a ser grande.

Em seguida, Antonio aparece vestido de são Jorge, com armadura e lança, e investe furiosamente contra o peito de Anita, e a mata. Um imenso caixão surge em cena e, ao redor dele, personagens que representam a igreja, a família e instituições conservadoras "celebram" ritualisticamente a morte. É Tânatos, aqui, que triunfa, e esta assustadora trupe entoa uma canção que diz que "a morte é vida”.

Mas Antônio investe contra eles, chora, está arrependido porque descobriu que está perdidamente apaixonado por Anita.

No dia seguinte, quando amanhece, Antonio é encontrado montado no cartaz, só de ceroulas, completamente doido (e sabemos que doido de amor), e é tirado de lá em uma camisa de força e levado numa ambulância para o hospício. Em cima da ambulância vemos Eros, rindo a valer. Provavelmente porque, agora, Antonio rendera-se ao amor.

\section{Relações amorosas}

Chamo agora a atenção do leitor para algumas aproximações que existem entre as duas obras, e, principalmente, de como "O País dos Contrários" retoma criativamente certos elementos formais presentes no "A tentação do Dr. Antonio", mantendo, com esta, uma relação intertextual explícita. 


\section{Breve quadro comparativo Agualusa-Fellini}

Agualusa

O país dos contrários

In: Estranhões e Bizarrocos

[histórias para adormecer anjos]

Conto

Gato Felini

Apaixona-se por uma vaca.

Incomoda-se com a indiferença de Graciosa (a vaca).

O gato "Felini sentava-se à noite em frente do estábulo e compunha canções...” para a vaca.

A vaca é grande, o gato Felini é pequeno.

O gato Felini cresce e fica do tamanho de um boi.

As gatas fogem do gato Felini.

O gato Felini vai para $\mathrm{O}$ País dos Contrários porque na terra onde nasceu olham-no como se fosse um monstro.

O elefante diz para o gato Felini que lá no País dos Contrários não será chamado de monstro (espaço de humanização).

O gato Felini se apaixona outra vez Agora, por uma vaquinha tão pequena que não lhe chega aos calcanhares.

\section{Fellini}

A tentação do Dr. Antonio

In: Boccaccio 70

Filme (media-metragem)

Dr. Antonio Mazzuollo

"Apaixona-se" (fica obcecado) pela enorme figura de Anita Ekberg, que usa um vestido decotado (deixando entrever seus fartos seios) e oferece um copo de leite.

Incomoda-se com a sensualidade de Anita Ekberg, no outdoor.

Dr. Antonio, à noite, observa Anita da janela de seu apartamento.

Anita Ekberg é grande, Dr. Antonio é pequeno (bate no calcanhar dela).

Anita fica pequena.

Dr. Antonio repudia Anita, diz que ela é o demônio.

Dr. Antonio chama Anita de "monstro".

Dr. Antonio enlouquece e (só então) se humaniza.

Antonio foi finalmente atingido pelo deus do amor, um Eros brincalhão e risonho que está no teto da ambulância que o leva para o hospício (ele 'perdeu' a cabeça). 
Outro aspecto que quero acrescentar às observações do quadro acima é que os contos do livro de Agualusa são dez, e me parece que pode haver aqui também referência ao Decameron, de Giovanni Bocaccio (que, por sinal, dá nome ao filme italiano que contém A tentação do Dr. Antônio: Bocaccio 70).

Como se sabe, Decameron, obra do século XIV, é constituída de dez jornadas de dez novelas (ou contos) cada uma, totalizando 100 contos. E, como salienta Otto Maria Carpeaux, a obra de Bocaccio critica a corrupção na igreja, o "Trionfo della Morte", a hipocrisia clerical, (CARPEAUX, Alhambra: 223-225). Ou seja, Decameron é um alentado libelo contra uma das mais influentes ideologias de seu tempo.

Não será outro o caminho de “A tentação do Dr. Antônio”. Nele, o italiano (e também católico) Fellini, retomando Bocaccio, ataca a hipocrisia, o moralismo e o patriarcalismo de católicos e conservadores em geral.

Igualmente Agualusa, em "O País dos Contrários”, investe contra o conservadorismo da sociedade, que desrespeita a alteridade e trabalha a favor do enquadramento e da normatização do amor.

Desde o título de seu livro (Estranhões e Bizarrocos...) o autor angolano nos avisa que seus personagens são "estranhões", muito estranhos ao senso comum, e "bizarrocos", palavra que remete a bizarro e que tanto pode ser o "extravagante, esquisito", o Outro, mas também o "gentil, nobre, generoso", como encontramos em um de nossos mais conhecidos dicionários (FERREIRA, 1999).

A este propósito, vale a pena mencionar o clássico ensaio de Freud escrito em 1919, "Das Unheimlich", O Estranho. Nesse texto, o autor, de uma perspectiva psicanalítica, estuda o efeito do "estranho" em obras literárias e na experiência psicológica. Freud pesquisa a palavra 'Unheimlich' em alemão (e também seus correlatos em latim, inglês, espanhol, francês, grego, italiano, português, árabe e hebreu), não apenas acepções de uso corrente como as em desuso ou que pertencessem a seu campo semântico. Encontra para tal expressão os significados: o estranho, o assustador, o sinistro, o que provoca medo e 
horror, o não-familiar, o desconhecido, o diferente, o estrangeiro, o suspeito, o inquietante, o que causa desconforto, o misterioso, o sobrenatural, o lúgubre, o demoníaco, tudo o que deveria ter se mantido oculto e secreto mas veio à luz. E, considera o autor, "a palavra alemã 'unheimlich' é obviamente o oposto de 'heimlich' ['doméstica'], 'heimisch' ['nativo'] - o oposto do que é familiar; e somos tentados a concluir que aquilo que é 'estranho' é assustador precisamente porque não é conhecido e familiar" (FREUD, 2006, p. 239).

Ao pesquisar 'heimlich', porém, o autor encontra inicialmente o que é familiar, conhecido, nativo, amistoso, doméstico, próprio da casa, confortável, seguro, contrário de selvagem, não-estranho, vizinho, intimo... mas também uma acepção onde 'heimlich' quer dizer secreto, escondido, oculto da vista, de forma que outros não possam perceber, furtivo, clandestino, fazer algo pelas costas, o que o recato obriga ocultar, amor, pecado, o escondido, lugar de encobrimento. Neste ponto, Freud destaca que "entre os seus diferentes matizes de significado a palavra 'heimlich' exibe um que é idêntico ao seu oposto, 'unheimlich"' (p. 242). "Da idéia de 'familiar', pertencente à casa, desenvolve-se outra idéia de algo afastado dos olhos de estranhos, algo escondido, secreto..." (p. 243). "Dessa forma, heimlich é uma palavra cujo significado se desenvolve na direção da ambivalência, até que finalmente coincide com o seu oposto, unheimlich. Unheimlich é, de um modo ou de outro, uma subespécie de heimlich" (p. 244).

Resolvendo esse aparente paradoxo, Freud descobre que o "estranho não é nada novo ou alheio, porém algo que é familiar e há muito estabelecido na mente, e que somente se alienou desta através do processo da repressão"(p. 258). O estranho seria o que uma vez foi secretamente familiar, foi reprimido (para o inconsciente) pelo ego e depois voltou (p. 262).

O par unheimlich/heimlich se constituiria, então, num campo de ambigüidade, de fronteiras difusas e até intercambiáveis.

No entanto, conforme descobriu a psicanálise, o ego exerce controle sobre a vida mental através da censura do material que julga ofensivo 
para os padrões convencionais de pensamento. Tal como o ego monolítico, que tenta calar as vozes que julga inconvenientes e não as reconhece como suas, o discurso hegemônico também não reconhece a familiaridade do outro. Pelo contrário, situa-o, através da linguagem, no locus suspectus do radicalmente outro. Suas estratégias de domínio são exacerbar a diferença, reprimi-la violentamente e não lhe reconhecer familiaridade.

É o que se empenha em fazer o personagem de Fellini, Antonio Mazzuolo, o censor, até que, através da benéfica invasão que sofre de seu inconsciente, acaba ouvindo as vozes que tentava, felizmente sem sucesso, sufocar.

$\mathrm{E}$ é o que faz os personagens coadjuvantes do gato Felini, no conto "O País dos contrários", obrigando o felino a sair pelo mundo para ver sua alteridade realizada.

Não são, portanto, gratuitas as relações intertextuais explícitas que o conto de Agualusa mantém com o filme de Fellini, e, através deste, com a obra de Bocaccio. Tais relações têm, suponho, a função de acrescentar ao texto do autor angolano portas de entrada, através da leitura intertextual, a significados de textos anteriores ao seu, para ampliá-lo e situá-lo numa tradição artística crítica, que condena a intolerância e a hipocrisia das sociedades humanas.

Como diz NITRINI (1997:164-165), citando Laurent Jenny, em Literatura Comparada:

A intertextualidade introduz um novo modo de leitura que solapa a linearidade do texto. Cada referência textual é o lugar que oferece uma alternativa: seguir a leitura encarando-a como um fragmento qualquer que faz parte da sintagmática do texto ou, então, voltar ao texto de origem, operando uma espécie de anamnésia, isto é, uma invocação voluntária do passado, em que a referência intertextual aparece como elemento paradigmático "deslocado" e provindo de uma sintagmática esquecida. Esses dois processos operando simultaneamente semeiam o texto com bifurcações que ampliam o seu espaço semântico.

Este "novo modo de leitura" nos mostra que as três obras artísticas, distantes até sete séculos entre si, se relacionam 
intertextualmente, construindo um grande tecido de crítica à sociedade conservadora que condena "estranhões", "bizarrocos", a vida em toda a sua diversidade, o amor em todas as suas formas, e os apaixonados em geral.

\section{Referências bibliográficas}

AGUALUSA, José Eduardo. Estranhões \& Bizarrocos [estórias para adormecer anjos]. Lisboa, Publicações Dom Quixote, 2000.

- O país dos Contrários. In: Estranhões \& Bizarrocos [estórias para adormecer anjos]. Lisboa, Publicações Dom Quixote, 2000.

BOCCACCIO, Giovanni. Decameron. Rio de Janeiro: Ediouro, s.d.

CARPEAUX, Otto Maria. História da Literatura Ocidental. v. 2. Rio de Janeiro, Editorial Alhambra, 1978.

FELLINI, Federico. A tentação do Dr. Antonio. In Boccaccio’70. produção Carlo Ponti. Versátil Home Film 2004. DVD.

FERREIRA, Aurélio Buarque de Holanda. Dicionário Aurélio século XXI. Versão 3. Rio de Janeiro: Nova Fronteira; Lexicon, 1999. CD-ROM.

FREUD, Sigmund. O estranho. In: Uma neurose infantil e outros trabalhos. Rio de Janeiro: Imago editora, 2006.

NITRINI, Sandra. Literatura Comparada: história, teoria e crítica. São Paulo: Editora da Universidade de São Paulo, 1997. 